\title{
Vertical distributions and seasonal variations of volatile phenols in Jiaozhou Bay
}

\author{
Dongfang Yang ${ }^{1,2,3, a}$, Fengyou Wang ${ }^{1,2, b}$, Sixi $\mathrm{Zhu}^{1,2}$, Yunjie $\mathrm{Wu}^{1,2}$ and Xiuqin \\ Yang ${ }^{1,2}$ \\ ${ }^{1}$ Research Center for Karst Wetland Ecology, Guizhou Minzu University, Guizhou Guiyang, \\ Guizhou Guiyang, China; \\ ${ }^{2}$ College of Chemistry and Environmental Science, Guizhou Minzu University, Shanghai, 550025, \\ China; \\ ${ }^{3}$ North China Sea Environmental Monitoring Center, SOA, Qingdao 266033, China. \\ adfyang_dfyang@126.com; ${ }^{b}$ Corresponding author; ${ }^{c}$ wangfy2001@yahoo.com.cn.
}

Keywords: Volatile phenols; Vertical distribution; Seasonal vatiation; Jiaozhou Bay

\begin{abstract}
We analyzed the spatial distributions and seasonal variations of volatile phenols in the bay mouth of Jiaozhou Bay in May, September and October in 1983. Results showed that volatile phenols contents were changing by means of vertical water's effect. Volatile phenols contents in surface waters were in orders of spring $>$ autumn $>$ summer, while for bottom waters were summer $>$ spring $>$ autumn. We found that the variations of volatile phenols contents in surface and bottom waters were determined by its settling process. In May and September, the distributions of volatile phenols contents were consist, while in October were reverse. The contents and variation ranges of volatile phenols in surface and bottom waters were tend to be conforming. The variations of volatile phenols in different sampling sites were determined by their locations. For instance, there were always low value regions of volatile phenols in bottom waters in the bay mouth. The spatial distributions and seasonal variations of volatile phenols were products of the horizontal water's effect and vertical water's effect, and were revealing the horizontal transfer process and vertical settling process of volatile phenols.
\end{abstract}

\section{Introduction}

Volatile phenols-contained wastewater is one of the most harmful and general industrial waster water in the whole world nowadays. Being a class of protoplasmic toxicants, volatile phenols have been critical environmental issues in marine environments in many countries and regions. Understanding the spatial distributions and seasonal variations of volatile phenols in marine environments is essential to identify their pollution and environmental impact [1-2]. Jiaozhou Bay is located in Shandong Province, eastern China. The aim of this paper was to analyz the spatial distributions and seasonal variations of volatile phenols in the bay mouth of Jiaozhou Bay in May, September and October in 1983, to reveal their horizontal transfer process and vertical settling process, and to provide basis for environmental remediation and protection.

\section{Materials and method}

Jiaozhou Bay $\left(35^{\circ} 55^{\prime}-36^{\circ} 18^{\prime} \mathrm{N}, 120^{\circ} 04^{\prime}-120^{\circ} 23^{\prime} \mathrm{E}\right)$ is located in the south of Shandong Peninsula, eastern China. It's a semi-closed bay, whose area, bay mouth width and average water depth and maximum water depth are $390 \mathrm{~km}^{2}, 2.5 \mathrm{~km}$ and $7.0 \mathrm{~m}$, respectively (Fig. 1). This bay is surrounding by cities of Qingdao, Jiaozhou and Jiaonan in the east, north and south, respectively, and the bay mouth is connecting with the Yellow Sea in the south. There are more than ten inflow rivers such as Loushan River, Licun River and Haibo River, all of which are seasonal rivers [3-4].

The data was provided by North China Sea Environmental Monitoring Center. The investigation on volatile phenols in five sampling sites (H34, H35, H36, H37 and H82) in Jiaozhou Bay waters 
was conducted in May, September and October 1983 (Fig. 1). The investigation and measurement of volatile phenols were followed by National Specification for Marine Monitoring [5].

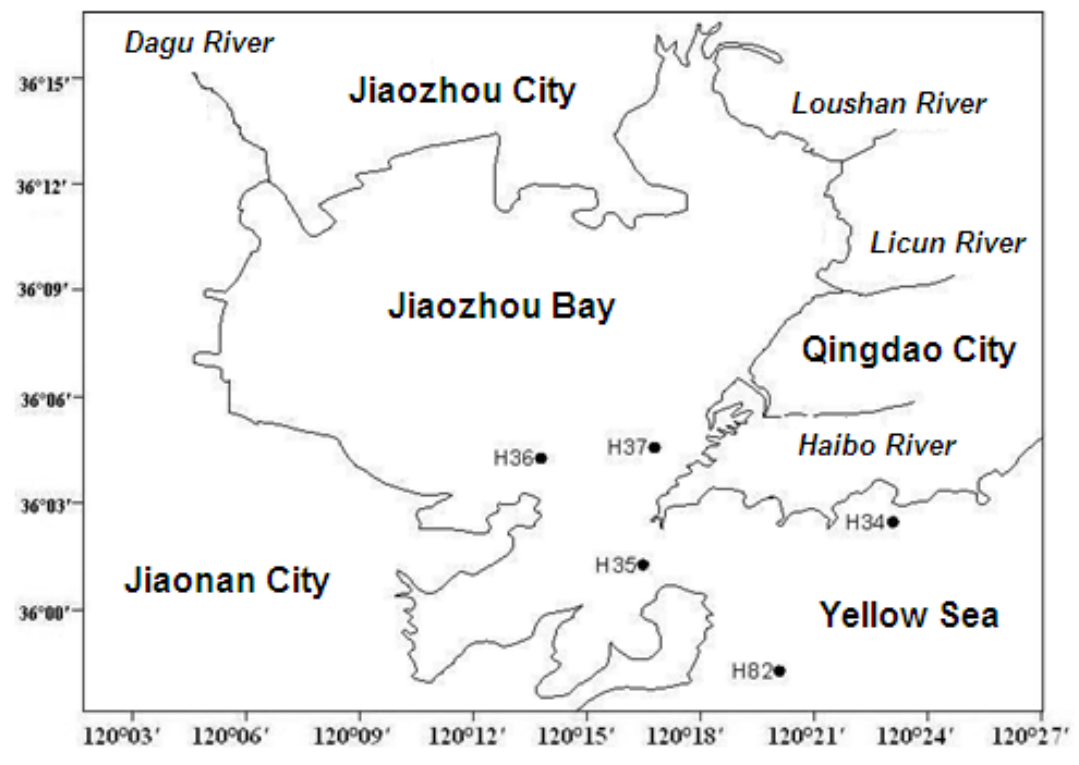

Fig.1 Geographic location and sampling sites of Jiaozhou Bay

\section{Results}

Seasonal variations of volatile phenols. Volatile phenols contents in surface waters in May, September and October 1983 were ranged from 0.50-2.50 $\mu \mathrm{g} \mathrm{L}^{-1}, 0.50-1.38 \mu \mathrm{g} \mathrm{L}^{-1}$ and $1.10-2.25 \mu \mathrm{g}$ $\mathrm{L}^{-1}$, respectively. May, September and October in study area are spring, summer and autumn, respectively. The seasonal variations of volatile phenols in surface waters were low $(0.50-2.50 \mu \mathrm{g}$ $\mathrm{L}^{-1}$ ), and were in orders of summer $>$ autumn $>$ spring. Meanwhile, volatile phenols contents in bottom waters in May, September and October 1983 were ranged from 0.25-1.85 $\mu \mathrm{g} \mathrm{L}^{-1}, 0.40-1.25$ $\mu \mathrm{g} \mathrm{L}^{-1}$ and 1.10-1.95 $\mu \mathrm{g} \mathrm{L}^{-1}$, respectively. The seasonal variations of volatile phenols in surface waters were also low $\left(0.25-1.95 \mu \mathrm{g} \mathrm{L}^{-1}\right)$, and were in orders of summer > spring > autumn.

Horizontal distributions of volatile phenols. We defined a direction from Site H36 or H37 inside the bay mouth to Site H34 outside the bay mouth. In May, volatile phenols contents in surface waters were showing gradient decreasing trends from $1.75 \mu \mathrm{g} \mathrm{L}{ }^{-1}$ to $1.00 \mu \mathrm{g} \mathrm{L}^{-1}$, and in bottom waters were also showing gradient decreasing trends from $1.85 \mu \mathrm{g} \mathrm{L}^{-1}$ to $0.25 \mu \mathrm{g} \mathrm{L}^{-1}$. In September, volatile phenols contents in surface waters were showing gradient increasing trends from $1.38 \mu \mathrm{g} \mathrm{L}^{-1}$ to $1.08 \mu \mathrm{g} \mathrm{L} \mathrm{L}^{-1}$, and in bottom waters were also showing gradient increasing trends from $1.25 \mu \mathrm{g} \mathrm{L}^{-1}$ to $0.40 \mu \mathrm{g} \mathrm{L}^{-1}$. In October, Cd contents in surface waters were showing gradient decreasing trends from $2.25 \mu \mathrm{g} \mathrm{L}{ }^{-1}$ to $1.44 \mu \mathrm{g} \mathrm{L} \mathrm{L}^{-1}$, while in surface waters were also showing gradient increasing trends from $1.35 \mu \mathrm{g} \mathrm{L}{ }^{-1}$ to $1.75 \mu \mathrm{g} \mathrm{L}{ }^{-1}$.

Vertical variations of volatile phenols. In according to the seasonal variations of volatile phenols in surface and bottom waters, we found that volatile phenols contents in bottom waters were increasing/decreasing along with the increasing/decreasing of phenols contents in surface waters. In order to reveal the vertical variations of volatile phenols, the contents in surface waters in the fiver sampling sites in May, September and October 1983 were subtracted from which in bottom waters, and the results were list in Table 1. For the whole year, the subtraction of volatile phenols contents in surface from which in bottom waters ranged from -0.75-0.95 $\mu \mathrm{g} \mathrm{L}^{-1}$, indicated that volatile phenols contents in surface and bottom waters were very closed. In May, the differences ranged from -0.75-0.95 $\mu \mathrm{g} \mathrm{L}^{-1}$. The subtractions in Sit H35 in the bay mouth, and Site H34 and H82 outside the bay mouth were positive, while for Sit H36 and H37 inside the bay mouth were negative. In September, the differences ranged from -0.38-0.68 $\mu \mathrm{g} \mathrm{\textrm {L } ^ { - 1 }}$. The subtractions in Site H34, H 35 and H36 were positive, while in Site H37 and H82 were negative. In October, the differences 
ranged from $-0.20-0.790 \mu \mathrm{g} \mathrm{L}^{-1}$. The subtractions in Site H34, H 35 and H36 were positive, in Site H82 and H37 were zero and negative, respectively.

Table 1 Results of subtracting Cd contents in surface waters from which in bottoms in the five sampling sites in May, September and October 1983

\begin{tabular}{|c|c|c|c|c|c|}
\hline Month & H34 & H35 & H36 & H37 & H82 \\
\hline May & Positive & Positive & Negative & Negative & Positive \\
\hline September & Positive & Positive & Positive & Negative & Negative \\
\hline October & Positive & Positive & Positive & Negative & Zero \\
\hline
\end{tabular}

\section{Discussion}

Seasonal variations process of Volatile phenols. In surface waters in the bay mouth of Jiaozhou Bay, volatile phenols contents were reaching the highest value $\left(2.50 \mu \mathrm{g} \mathrm{L}^{-1}\right)$ in May , and then were decreasing in September $\left(1.38 \mu \mathrm{g} \mathrm{L}^{-1}\right)$, and were increasing in autumn $\left(2.25 \mu \mathrm{g} \mathrm{L}^{-1}\right)$. Hence, volatile phenols in surface waters were in orders of summer $>$ autumn $>$ spring. The reason was that the major source of volatile phenols was marine current, which was reaching the climax in spring. In summer, the major source was river flow, yet whose source strength was reducing while was reaching the bay mouth. In autumn, the major source was overland runoff, whose source strength was strong in areas closed to the bay mouth. It could be seen that volatile phenols contents in bottom waters were determined by which in surface waters by means of vertical water's effect [6], as well as by accumulation effect in bottom waters. Hence, volatile phenols contents in bottom waters were in order of summer $>$ spring $>$ autumn.

Settling process of volatile phenols. Volatile contents in waters were changing a lot after passing through the water body by means of the vertical water's effect [6]. Due to the small molecular weight and strong hydrophilicity, volatile phenols could be easy to be combined with zooplankton and phytoplankton and floating particles. The activities of zooplankton and phytoplankton were increasing in summer [4], which were able to enhancing the adsorption capacity of suspended particulate matters due to the large production of colloid. Hence, a large amount of volatile phenols was absorbed and brought to the sea bottom under the force of gravity and current [2].

Temproal settling of volatile phenols. Volatile phenols in surface waters were in orders of summer $>$ autumn $>$ spring. Meanwhile, volatile phenols contents in bottom waters were in order of summer $>$ spring $>$ autumn. Volatile phenols contents in bottom waters were increasing/decreasing along with the increasing/decreasing of phenols contents in surface waters. The reason was that volatile phenols were settling to the bottom waters continuously. Although volatile phenols contents in autumn were lower than in spring in surface waters, an inverse phenomenon was occurred due to the continuous settling.

Spatial settling of volatile phenols. The distributions of volatile phenols in surface waters and bottom waters were consisting in May and September. The reason was that a lot of volatile phenols were absorbing and settling to the bottom waters in hot seasons. As time went by, a large amount of volatile phenols were accumulating in the bottom waters, leading to the increasing of contents in bottom waters in autumn. Hence, the distributions of volatile phenols in surface waters and bottom waters were inversing in October.

Variation settling of volatile phenols. In variation scale, the variation ranges of volatile phenols contents in surface and bottom waters were basically the same in May, September and October. The higher volatile phenols contents in surface waters, the higher volatile phenols contents in bottom waters. The consistency of volatile phenols contents in surface and bottom waters was showing the rapid and continuous settlement of volatile phenols.

Vertial settling of volatile phenols. In variation scale, volatile phenols contents in surface and bottom waters were very closed in May, September and October. That indicated that volatile phenols could be transferred to bottom waters rapidly without significant loss by means of vertical water's effect [8] . The loss range was $0.50-0.25 \mu \mathrm{g} \mathrm{L}{ }^{-1}$ to $2.25-1.95 \mu \mathrm{g} \mathrm{L}^{-1}$, that was $0.25-0.30 \mu \mathrm{g}$ 
$\mathrm{L}^{-1}$. Hence, volatile phenols contents in surface and bottom waters were close and keeping consistent.

Regional settling of volatile phenols. In regional scale, the subtractions of volatile phenols contents in surface waters from which in bottom waters were also changing along with time. These differences were indicating the variations of volatile phenols contents in surface and bottom waters. River flow, overland runoff and marine current were the major sources of volatile phenols in the bay. Once volatile phenols was discharged to the bay from the sources, it was firstly reaching the surface waters, and than was settling to the bottom waters rapidly and continuously. In Sit H34 located in the northwest outside the bay mouth, the continuous inputs of volatile phenols from the overland runoff resulted in the higher contents in surface waters than in bottom waters in different seasons. Site H35 was located in the bay mouth, in where the flow rate was very high. Hence, by means of the vertical water's effect and low value effect, volatile phenols in bottom waters in this region were always lower than in surface waters. Site H36 was located in southwest inside the bay, in where volatile phenols were mainly generated from overland runoff. There was little overland runoff in May, leading to the low volatile phenols contents in surface waters. However in September and October, volatile phenols contents were increasing due to the increasing of overland runoff. Site H37 was located in the northwest inside the bay, in where river flow was the major source of volatile phenols. Due to the rapid and continuous settling, a lot of volatile phenols were accumulating in bottom waters, and were leading the higher contents in bottom waters than in surface waters. Site H82 was located in the south outside the bay mouth, in where marine current was the major source of volatile phenols. Once the marine current was dominated the sources in May in this region, volatile phenols contents were higher in surface waters than in bottom waters. Once the marine current was stop in September, volatile phenols contents were lower in surface waters than in bottom waters. Once there was no source in October, volatile phenols contents in both surface and bottom waters were tend to be same.

\section{Conclusion}

Volatile phenols in surface waters were in orders of summer $>$ autumn $>$ spring, while in bottom waters were in order of summer $>$ spring $>$ autumn. Volatile phenols contents in bottom waters were increasing/decreasing along with the increasing/decreasing of phenols contents in surface waters. Volatile contents in waters were changing a lot after passing through the water body by means of the vertical water's effect. The distributions of volatile phenols in surface waters and bottom waters were consisting in May and September, while for October were inversing. Volatile phenols contents in surface and bottom waters were very closed in May, September and October. That indicated that volatile phenols could be transferred to bottom waters rapidly without significant loss by means of vertical water's effect. The variations of volatile phenols contents in different locations were determining by pollution sources, vertical water' effect and horizontal water's effect.

\section{Acknowledgement}

This research was sponsored by Doctoral Degree Construction Library of Guizhou Nationalities University, Education Ministry's New Century Excellent Talents Supporting Plan (NCET-12-0659), Education Ministry's New Century Excellent Talents Supporting Plan (NCET-12-0659), Project of Outstanding Technological Educators of Governor of Guizhou ([2012]71), Project of Low Carbon Technology Plan of Guiyang (2012205]), Project of Science and Technology Foundation of Guiyang (LKM[2012]05), Special Research Projects of High Level Talents of Guizhou Province (TZJF-2011-44), the China National Natural Science Foundation (31560107) and Research Projects of Guizhou Nationalities University ([2014]02), Research Projects of Guizhou Province Ministry of Education (KY [2014] 266), Research Projects of Guizhou Province Ministry of Science and Technology (LH [2014] 7376). 


\section{Reference}

[1] Yang DF, He HZ, Zhu SX, et al.: Materials, Environmental and Biological Engineering, 2015, p. 343-346.

[2] Yang DF, He HZ, Gao J, et al.: Materials, Environmental and Biological Engineering, 2015, p. 1103-1106.

[3] Yang DF, Chen Y, Gao ZH, et al.: Chinese Journal of Oceanology and Limnology, Vol. 23 (2005), pp. 72-90.

[4] Yang DF, Wang F, Gao ZH, et al.: Maine Science, Vol. 28(2004): 71-74. (in Chinese with English abstract)

[5] State Ocean Administration. The specification for marine monitoring: Beijing, Ocean Precess, (1991).

[6] Yang DF, Wang FY, He HZ, et al.: Proceedings of the 2015 international symposium on computers and informatics, 2015, p. 2655-2660. 